\title{
Efecto de la inclusión de tres niveles de contenido ruminal de bovinos por medio de la evaluación del ensilaje de maíz (Zea mays)
}

\author{
Luis Alberto Villeda Lanuza \\ Gloria Recinos \\ Ministerio de Agricultura, Ganadería y Alimentación
}

Fecha de recepción: 25/05/2016

Fecha de aceptación: 02/05/2017

\begin{abstract}
Resumen
El objetivo de la presente investigación fue encontrar alternativas de alimentación de ganado bovino para la época seca, por medio de la inclusión de diferentes niveles de contenido ruminal de bovino en el ensilaje de maíz, se evaluó la calidad del ensilaje a través del análisis bromatológico químico proximal, determinación de pH, porcentaje de pérdidas para todos los ensilados. Se utilizaron 16 micro-silos, con un diseño estadístico completamente al azar, en cuatro tratamientos de cuatro repeticiones siendo un micro-silo la unidad experimental. El estudio tuvo una duración de 108 días, abriendo los micro-silos para su análisis en el laboratorio de bromatología, cuarenta días después de ser elaborados. Los tratamientos evaluados fueron: testigo $100 \%$ de maíz picado y $0 \%$ de contenido ruminal; tratamiento $195 \%$ maíz picado y $5 \%$ de contenido ruminal; tratamiento $290 \%$ maíz picado y $10 \%$ contenido ruminal y tratamiento $385 \%$ maíz picado y $15 \%$ contenido ruminal. Bajo las condiciones en las que se realizó la presente investigación, se puede mencionar que se encontraron diferencias en cuanto a la calidad nutricional del ensilaje de maíz con contenido ruminal en relación al porcentaje de materia seca, porcentaje de proteína cruda y $\mathrm{pH}$, sin embargo, sí se encontraron diferencias con respecto al porcentaje de fibra neutro detergente, porcentaje de fibra ácido detergente, porcentaje de lignina y porcentaje total de nutrientes digestibles. Por lo que podemos recomendar utilizar un $10 \%$ de contenido ruminal sobre la materia fresca del maíz para ensilar.
\end{abstract}

\section{Palabras clave}

Contenido ruminal, ganado bovino, alimentación, ensilaje

\begin{abstract}
The objective of this research was to find alternative cattle feeding during the dry season, through the inclusion of different levels of bovine rumen content on the silage corn, was evaluated the quality of silage through the Food Safety Laboratory proximal chemical analysis, pH determination, lost of all silage \%. Using 16 mirco-silage, with a completely randomized desing, in four treatments in four replications being a micro-silage the experimental unit. The study had duration of 108 days, open micro-silage for laboratory analysis produced forty days after. The treatments were: $100 \%$ of chopped corn and $0 \%$ of rumen content; $95 \%$ of chopped corn and $5 \%$ of rumen content; $90 \%$ of chopped corn and $10 \%$ of rumen content, $85 \%$ of chopped corn and $15 \%$ of rumen content. Under conditions in which this research was conducted, can conclude that found differences in \% dry matter, \% crude protein and $\mathrm{pH}$, however differences were found regarding the percentage neutral detergent fiber, percentage acid detergent fiber, percentage lignin and percentage total digestible nutrients. As we recommend the use $10 \%$ of rumen contents on the fresh matter of corn silage to feed cattle.
\end{abstract}

\section{Key words}

Rumen content, cattle, feeding, silage 


\section{Introducción}

El ensilaje representa una alternativa de solución al problema de alimentación del ganado, permite la conservación de forrajes que se producen durante la época de lluvias logrando atenuar el déficit nutricional observado en los hatos bovinos durante la época crítica del año. (Colombatto et al. 2006) La búsqueda de fuentes alimenticias que contribuyan a incrementar la eficiencia productiva y económica de la explotación animal actual, ha resultado en el empleo de residuos orgánicos como el contenido ruminal, productos de agroindustrias y de las mismas empresas pecuarias, el cual hasta hace poco eran considerados desperdicios contaminantes. El contenido ruminal es un residuo producto de la matanza de los animales beneficiados en los mataderos, es el alimento ingerido por los rumiantes que es desechado al momento del sacrificio. Es una mezcla de material no digerido que tiene la consistencia de una masa, color amarillo verdoso y un olor característico muy intenso cuando está fresco, además posee gran cantidad de microflora rumial y productos de la fermentación ruminal. (Chaverra 2000) El contenido ruminal en los rastros en su mayoría es desechado en las alcantarillas y ríos, produciendo un alto índice de contaminación ambiental y poniendo en peligro la salud humana. (De la Raza-Delgado 2005) En la región no existe la suficiente información acerca del contenido ruminal de bovino, por lo que esta investigación se realiza para obtener este conocimiento. Las consideraciones anteriores motivaron la realización de la presente investigación.

\section{Materiales y métodos}

El presente estudio se realizó en la finca El Chagüitón ubicada en la aldea El Milagro, municipio de Masagua, departamento de Escuintla, se encuentra en una zona de vida de "Bosque húmedo subtropical cálido", a una altitud de 100 msnm, con temperaturas que oscilan entre 21 a $25^{\circ} \mathrm{C}$, precipitación pluvial de 1826 mm/año y humedad relativa de $90 \%$.

El trabajo de campo se realizó en las siguientes fases:
Fase I: Se prepararon 0.03 hectáreas con una pasada de arado y un día antes de la siembra, se trabajó la tierra con la rastra como preparación para su siembra. La semilla fue protegida con un insecticida con el principio activo carbámico que actúa por contacto e ingestión, formulado en suspensión acuosa (flowable), para el tratamiento de la semilla de maíz antes de la siembra, proporcionando protección durante la germinación y la primera etapa de desarrollo del cultivo.

Fase II: El terreno fue surqueado a $85 \mathrm{~cm}$ de distancia entre cada surco. La siembra del maíz fue manual; aplicando de 3 a 5 semillas por postura cada $25 \mathrm{~cm}$ entre sí. La semilla utilizada fue ICTA HB 83 porque esta es una variedad que se desarrolla en un ambiente como el del área de estudio. Siendo fertilizado con $4.5 \mathrm{Kg}$. de triple 15 al momento de la siembra con aplicación directa al surco y veinticinco días, después de la siembra se fertilizó con urea (Nitrógeno al 46 \%) a razón de $4.5 \mathrm{Kg}$. se aplicó dentro del surco. El cultivo fue regado en dos ocasiones, siendo la primera un día después de la siembra, y el segundo riego fue a los 40 días. La siembra se llevó a cabo a finales de noviembre.

Fase III: A los 64 días de siembra, se muestreó al azar cinco lugares distintos del cultivo, se cortaron algunas mazorcas y luego se partieron por la mitad con machete buscando el estado mazoso lechoso, y así poder establecer la fecha de corte, la cual fue al día 68 de la siembra del maíz.

Fase IV: El día 68 después de la siembra, se inició el proceso de ensilado de los cuatro tratamientos. Al mismo tiempo se obtuvo en fresco el contenido ruminal de bovino en el rastro municipal del municipio de Masagua, para la elaboración de dieciséis micro-silos para ser conservados mediante el proceso del ensilaje en condiciones de ausencia de luz.

La elaboración de los micro-silos consistió en introducir el material por capas (una capa de maíz picado y luego una capa de contenido ruminal de bovino) con sus diferentes niveles de inclusión sobre el ensilaje de maíz; tratamiento uno testigo 100 $\%$ de maíz picado, tratamiento dos $5 \%$ contenido ruminal, tratamiento tres $10 \%$ contenido ruminal 
y tratamiento cuatro $15 \%$ de contenido ruminal. El contenido ruminal se obtuvo de animales beneficiados en el Rastro Municipal de Masagua, Escuintla, el cual se obtiene en el momento del destace directamente del estómago del animal. Este se transportó en bolsas plásticas colocadas en una hielera, esto para mantener la frescura del producto y sus propiedades, manteniendo en un estado adecuado el licor ruminal. El contenido ruminal se ensiló el mismo día que fue obtenido.

Se elaboraron cuatro repeticiones para cada tratamiento, siendo un total de dieciséis micro-silos, con una capacidad de aproximadamente $3-5 \mathrm{Kg}$. estos se observaron que estuvieran limpios y desinfectados, para luego realizar el proceso de ensilaje. El material se compactó dentro de cada contenedor hasta dejar el espacio con el objetivo de colocar una moneda de quetzal, la cual se utilizó para la base de una vela. Esta posteriormente se encendió y se colocó tapa roscada, se selló con cinta adhesiva la rosca con el objetivo de lograr hermetismo y identificando el proceso debidamente con su tratamiento y repetición. Al agotarse el oxígeno la vela se apagó; posteriormente se taparon con papel periódico para evitar la entrada de luz. Al terminar de ensilar los dieciséis micro silos, se transportaron hacia el Laboratorio de Bromatología de la Facultad de Medicina Veterinaria y Zootecnia, donde se almacenaron por cuarenta días.

Fase V: Los dieciséis micro-silos se llevaron al Laboratorio de Bromatología, una semana después de haberlos realizado, para su almacenamiento y ser abiertos a los 40 días de elaborados. A los 40 días de almacenados se procedió a abrir los micro-silos para realizar los análisis correspondientes.

Fase VI: Para las variables anteriormente mencionadas se efectuó el Análisis de Varianza (ANDEVA), y al encontrar diferencias significativas entre tratamientos, se procedió a efectuar la prueba de comparación de medias de Tukey.

\section{Resultados y discusión}

\section{Cuadro 1}

Porcentaje de materia seca, proteína cruda, fracciones de fibra, total de nutrientes digestibles y $\mathrm{pH}$ del ensilado de maíz con diferentes niveles de contenido ruminal de bovino en micro-silos

\begin{tabular}{|c|c|c|c|c|}
\hline Variables & Testigo & $\begin{array}{l}5 \% \text { contenido } \\
\text { ruminal }\end{array}$ & $\begin{array}{l}10 \% \text { contenido } \\
\text { ruminal }\end{array}$ & $\begin{array}{l}15 \% \text { contenido } \\
\text { ruminal }\end{array}$ \\
\hline Materia seca & 21.69 (a) & $21.44(a)$ & 19.87 (a) & 22.65 (a) \\
\hline Proteína cruda & 7.43 (a) & 8.45 (a) & 8.13 (a) & 8.08 (a) \\
\hline Fibra ácido detergente & $18.49(a)(b)$ & 19.35 (a) & $17.70(b)$ & $18.73(\mathrm{a})$ \\
\hline Fibra neutro detergente & 60.01 (b)(c) & $62.36(a)$ & $59.05(c)$ & $60.52(b)$ \\
\hline Lignina & $16.64(b)$ & 18.29 (a) & 13.47 (c) & $11.63(d)$ \\
\hline Total de nutrientes digestibles & 73.08 (b) & $72.75(b)$ & $73.99(\mathrm{a})$ & 73.13 (b) \\
\hline $\mathrm{pH}$ & 3.84 (a) & 3.37 (a) & 3.77 (a) & 3.34 (a) \\
\hline
\end{tabular}

Fuente: Elaboración propia

*Medias con igual letra no presentan diferencias estadísticas significativas $(p \geq 0.05)$ 
El análisis estadístico que se observa en el Cuadro 1, indica que no se encontraron diferencias significativas dentro de los tratamientos evaluados para la materia seca $(p \geq 0.05)$ y al comparar los resultados del presente estudio son similares con los reportados por Rivas, et al (2006), que reportó un $77.30 \%$ de humedad y de $22.70 \%$ de materia seca con grano lechoso. Rodenas, et al. (1999) reportan en las tablas de composición de alimentos para animales, valores de $77 \%$ de agua y $23 \%$ de materia seca de maíz (procedente de Nueva Concepción, Escuintla), ensilado en estado de grano lechoso; lo que se puede observar en los resultados del presente trabajo que son similares a los reportados por los autores anteriormente mencionados.

Al evaluar la proteína cruda tampoco se encontraron diferencias significativas entre los tratamientos. Al comparar estos resultados con los reportados en otras investigaciones se observa que, Rodenas et al. (1999), en las tablas de composición de alimentos para animales, ensilado de maíz efectuado por ICTA-INCAP, presentan valores que oscilan entre $5.98 \%$ a $7.53 \%$ de proteína, Portillo (1995) reporta que al evaluar cuatro variedades de maíz para guatera con diferentes niveles de fertilización Nitrogenada, obtuvo valores entre $8.62 \%$ y 11.78 \% para la proteína cruda; Vas Martins et al. (2006), presentan resultados de más de ocho años de análisis de muestras recibidas en el laboratorio del INIA La Estanzuela (Uruguay) valores en promedio de $7.8 \%$, máximos $12.7 \%$ y mínimos de $5.4 \%$ para la proteína cruda. Por otro lado FEDNA (2004) reporta valores de $7.62 \%$, para la proteína.

Todos estos valores son similares a los encontrados en esta investigación, por lo que está entre los rangos anteriormente mencionados. Al mismo tiempo se puede inferir que la adición de contenido ruminal no cambia significativamente el contenido de proteína cruda (Kung y Shaver 2001).

Para el caso de la Fibra Ácido Detergente no se encontró diferencia significativa $(p \geq 0.05)$ entre los tratamientos dos, cuatro y uno, ni en los tratamientos uno y tres pero sí se encontró diferencia significativa entre los tratamientos dos, cuatro y el tratamiento tres, ya que el tratamiento dos obtuvo el mayor re- sultado con (19.35\%) y el tratamiento tres el menor con (17.70 \%). Así mismo Vas Martin et al. (2006), reporta valores para la Fibra Acido Detergente, que van de $45.9 \%$ y $36.1 \%$ en dos años diferentes de muestras, los cuales están arriba de los encontrados en este estudio que en promedio es de $18.56 \%$.

Por su parte Rodenas, et al. (1999) mencionan que para la fibra ácido detergente los valores deben encontrarse en un rango de $32.26 \%$ y $39.75 \%$ estos se encuentran más elevados que los reportados en este estudio.

Para la Fibra Neutro Detergente el análisis estadístico indica que existe una diferencia significativa $(p \leq 0.5)$ entre los tratamientos ya que el tratamiento dos obtuvo el porcentaje más alto y este presenta diferencia estadística significativa con el tratamiento cuatro. Estos resultados con los reportados por Vas Martin et al. (2006) muestra valores en promedio de $51.5 \%$, máximos de $65.5 \%$ y mínimos de $40.7 \%$, que se encuentran en el rango del promedio de la Fibra Neutro Detergente del experimento evaluado. Rodenas, et al. (1999) mencionan para la fibra neutro detergente, valores mínimos de $58.83 \%$ y máximos de $72.72 \%$, dentro de los se enmarcan los encontrados en este estudio.

Asimismo, al evaluar la lignina se observa que sí existe una diferencia estadística significativa $(p \geq 0.05)$ entre los tratamientos evaluados siendo el tratamiento dos el que mayor resultado obtuvo con $18.29 \%$ y el tratamiento cuatro el que menor resultados presentó $11.63 \%$, y en las Latin american tables (1972) se reporta el ensilado de maíz $8.1 \%$ para la lignina valor que está debajo de los encontrados en este estudio que en promedio es de $15 \%$. Por último, señalan que los valores para la fracción de lignina deben de estar en un rango de 5.53 \% - 7.70 \% para un buen ensilado de maíz, lo que nos indica que al momento de aplicar más contenido ruminal reduce los niveles de lignina.

Además se observó que existe una diferencia estadística significativa ( $p$ es menor a 0.5 ) entre los tratamiento evaluados en cuanto al Total de Nutrientes Digestibles, siendo diferente el tratamiento tres con $10 \%$ de contenido ruminal obtuvo el mayor 
porcentaje de TND con un resultado de $73.99 \%$ en comparación con los tratamientos cuatro, uno, dos; y en los tratamientos cuatro, uno, dos no se presentaron diferencias estadísticas significativas entre los tratamientos. Rodenas, et al. (1999) en las tablas de composición de alimentos para animales presentan valores para el porcentaje de TND, al hacer referencia a los ensilados de maíz, desarrollado en el ICTA-INCAP que oscilan desde un 54 $\%-78.81 \%$. Por otro lado, en el ensilado de maíz de la ENCA los valores son $49.86 \%-58.46 \%$; los cuales son similares a los valores encontrados en este estudio.

Para el caso del pH no existe diferencia estadística significativa $(p \geq 0.05)$ entre los tratamientos evaluados, los resultados que se encontraron en este estudio al ser comparados con los reportados en otras investigaciones se puede mencionar que según Gutiérrez (1996), indica que el pH de los ensilados se estabiliza cuando este valor está por debajo de 4.2; Jahn y Confré (2008) reportan similares resultados a los encontrados en este experimento en ensilados de maíz, con valores entre 3.5 y 4.5 de $\mathrm{pH}$.

De la Roza y Martínez (1998), reportan valores promedio de los ensilados de maíz elaborados en la región de Asturia (España) en 1996 para el pH valores con rangos 3.50 a 5.72 y una media de 3.89. Vas Martins et al. (2006) presenta valores para el $\mathrm{pH}$ de 3.88 en promedio, máximos de 5.25 y mínimos de 1.77 que se encuentran dentro del rango de esta investigación, un 3.34 - 3.84 se puede considerar un $\mathrm{pH}$ óptimo, estable y adecuado de fermentación.

\section{Conclusiones}

No existen diferencias en la calidad nutricional del ensilaje de maíz con contenido ruminal en términos de porcentaje materia seca, porcentaje proteína cruda y $\mathrm{pH}$.

Existen diferencias en la inclusión de distintos niveles de contenido ruminal de bovino, en relación al porcentaje de Fibra Neutro Detergente, porcentaje de Fibra Acido Detergente, porcentaje de Lignina y porcentaje Total de Nutrientes Digestibles.

El tratamiento con diez por ciento de contenido ruminal presentó mayor porcentaje de TND (73.99\%).

\section{Referencias}

Colombatto, D. et al. (2003). "In vitro evaluation of fibrolytic enzymes as additives for maize (Zea mays L.) silage. II: Effects on rate of acidification, fibre degradation during ensiling and rumen fermentation". Anim. Feed Sci. Technol., pp, 129-143.

Chaverra, H. (2000). "El ensilaje en la alimentación del ganado vacuno". Revista IICA, pp 5-8.

De la Raza-Delgado, B. (2005). El ensilado en zonas húmedas y sus indicadores de calidad. IV Jornadas de Alimentación Animal. Laboratorio de Mouriscade. Lalín (Pontevedra).

FEDNA (Fundación Española para el Desarrollo de la Nutrición Animal, ES). (2004). Tabla de Forrajes FEDNA de composición y valor nutritivo en forrajes y subproductos fibrosos húmedos. Madrid, ES. (en línea) Consultado $10 \mathrm{feb}$ 2011.Disponible www.etsia.upm.es/fecha/forrajes/maisilo .

Jahn, BE. y P. Confré. (2008). Ensilaje de maíz: cantidad no es igual a calidad. Red Agrícola Comunicaciones LTDA. Santiago de Chile. (en línea). Consultado 3 de feb. 2011. Disponible en www.redagricola.com/content/view23/36/

Kung, L. y R. Shaver. (2001). "Interpretation and use of silage fermentation. Analysis reports. In: focus on forage". Wisconsin Team Forage. Vol. 3: $N^{\circ} 13$

Rivas, MA et al. (2006). Rendimiento y calidad de ensilado de seis genotipos de maíz cosechados en dos estados de madurez. Programa producción de semillas, Colegio de Post-graduados Campus Montecillo. Universidad Au- 
tónoma de Puebla. (en línea). Consultado 2 de feb. 2011. Disponible en www.engormix. com/rendimiento_calidad_ensilado_seis_s_ articulos_968_AGR.htm.

Rodenas Argueta, MA et al. (1999). Tablas de valor nutricional de alimentos para animales en Guatemala. Guatemala, Universidad de San Carlos de Guatemala, Dirección General de Investigación.
Vas Martins, D et. al. (2006) Ensilaje de maíz como componente de la dieta en la fase de terminación de novillos. Revista INIA Producción Animal. (en línea) consultado 2 de feb. 2011. Disponible www.inia.org.uy/publicaciones/ documentos/ara/ara_169.pdf. 